\title{
Spiculoic Acids A and B, New Polyketides Isolated from the Caribbean Marine Sponge Plakortis angulospiculatus
}

Xin-Hui Huang, Rob van Soest, Michel Roberge and Raymond J. Andersen*

\section{Supporting Information}




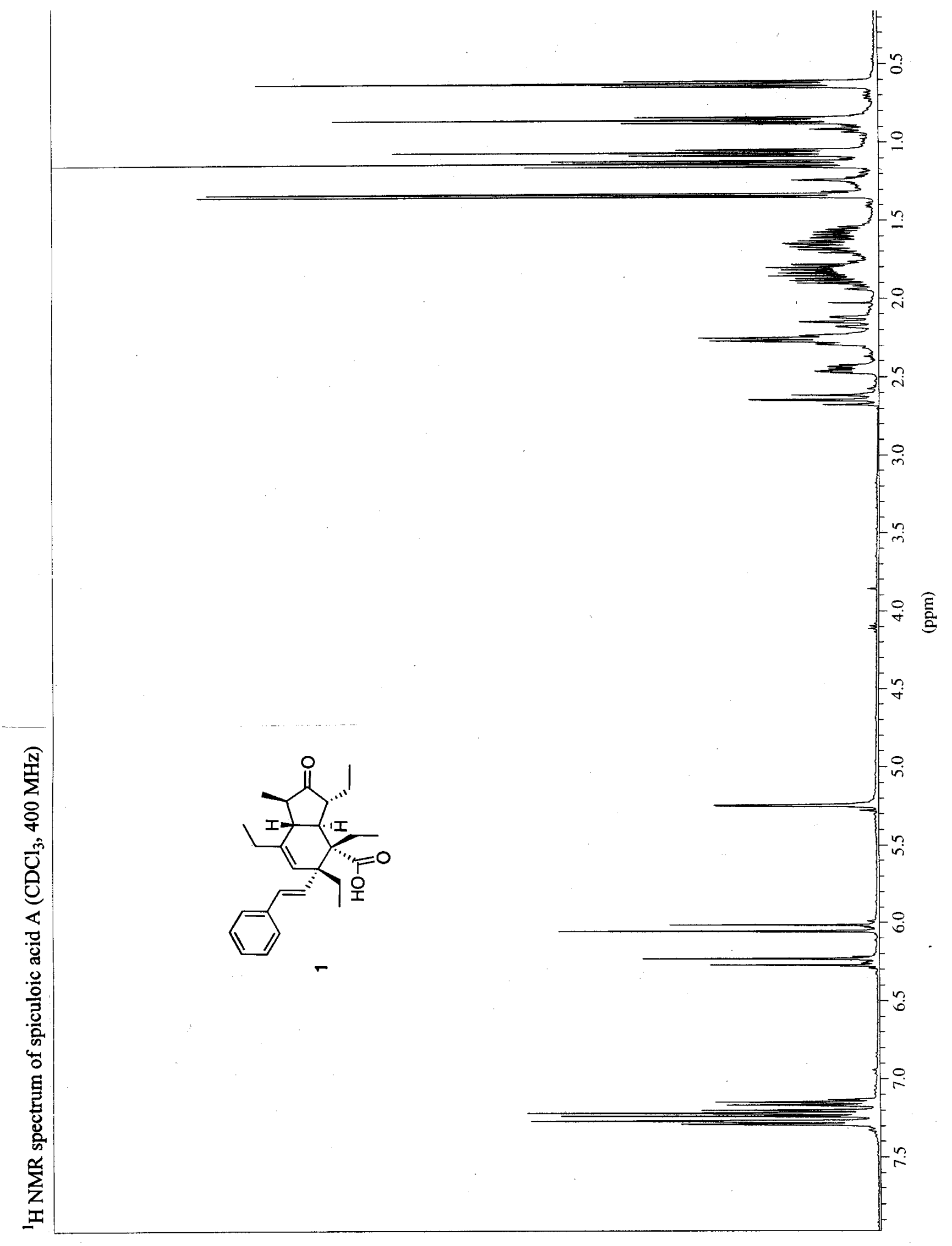




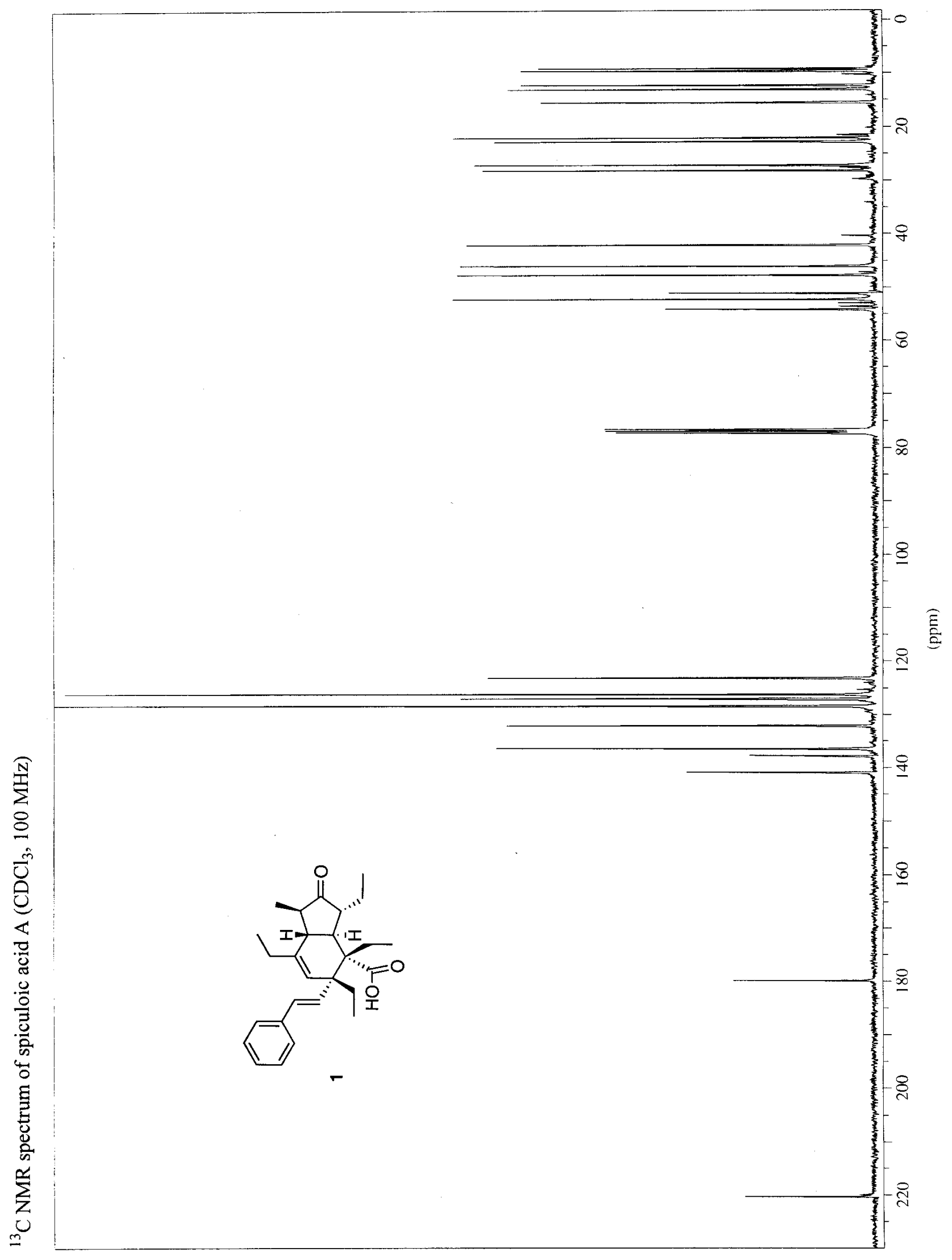




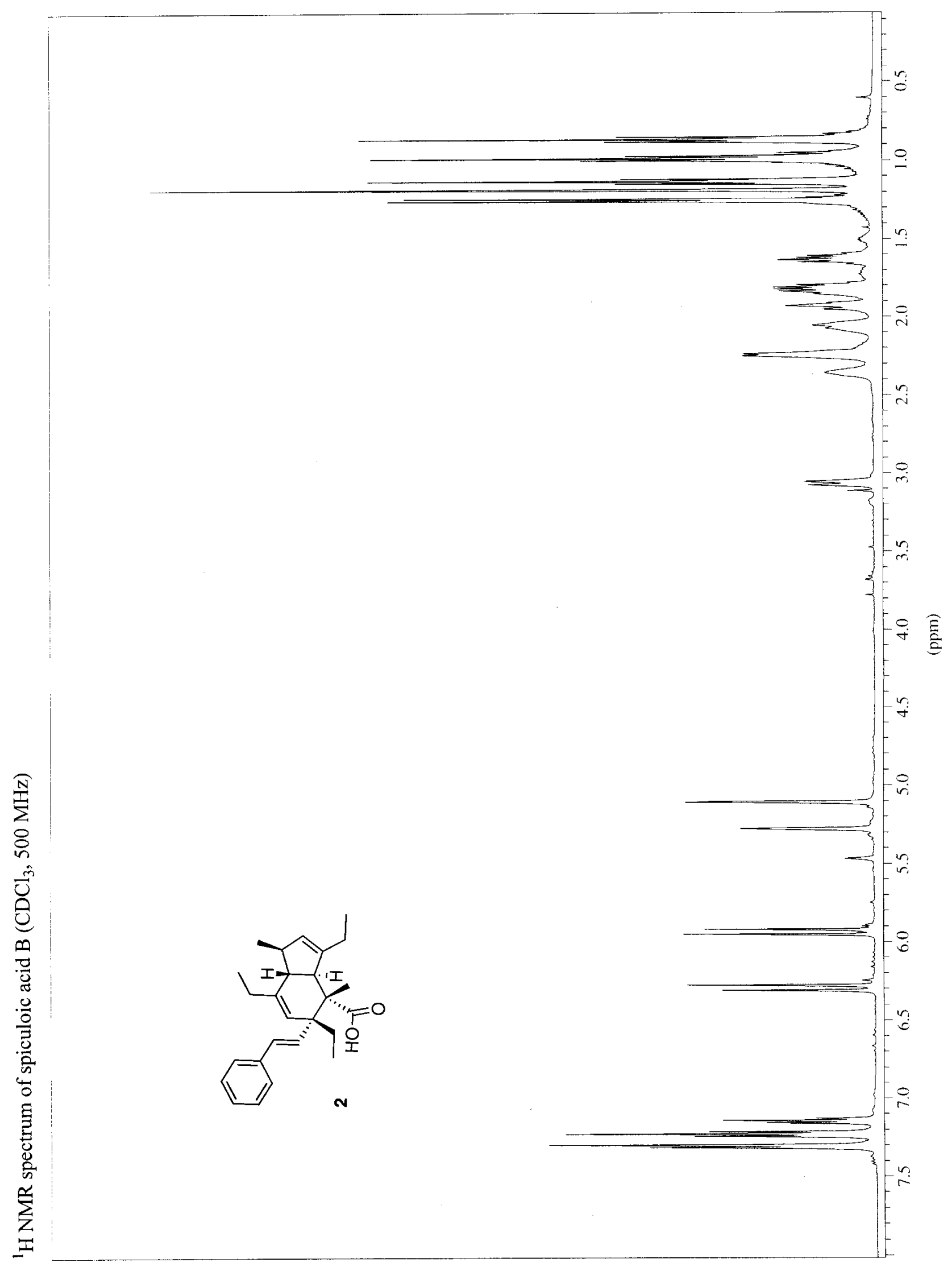




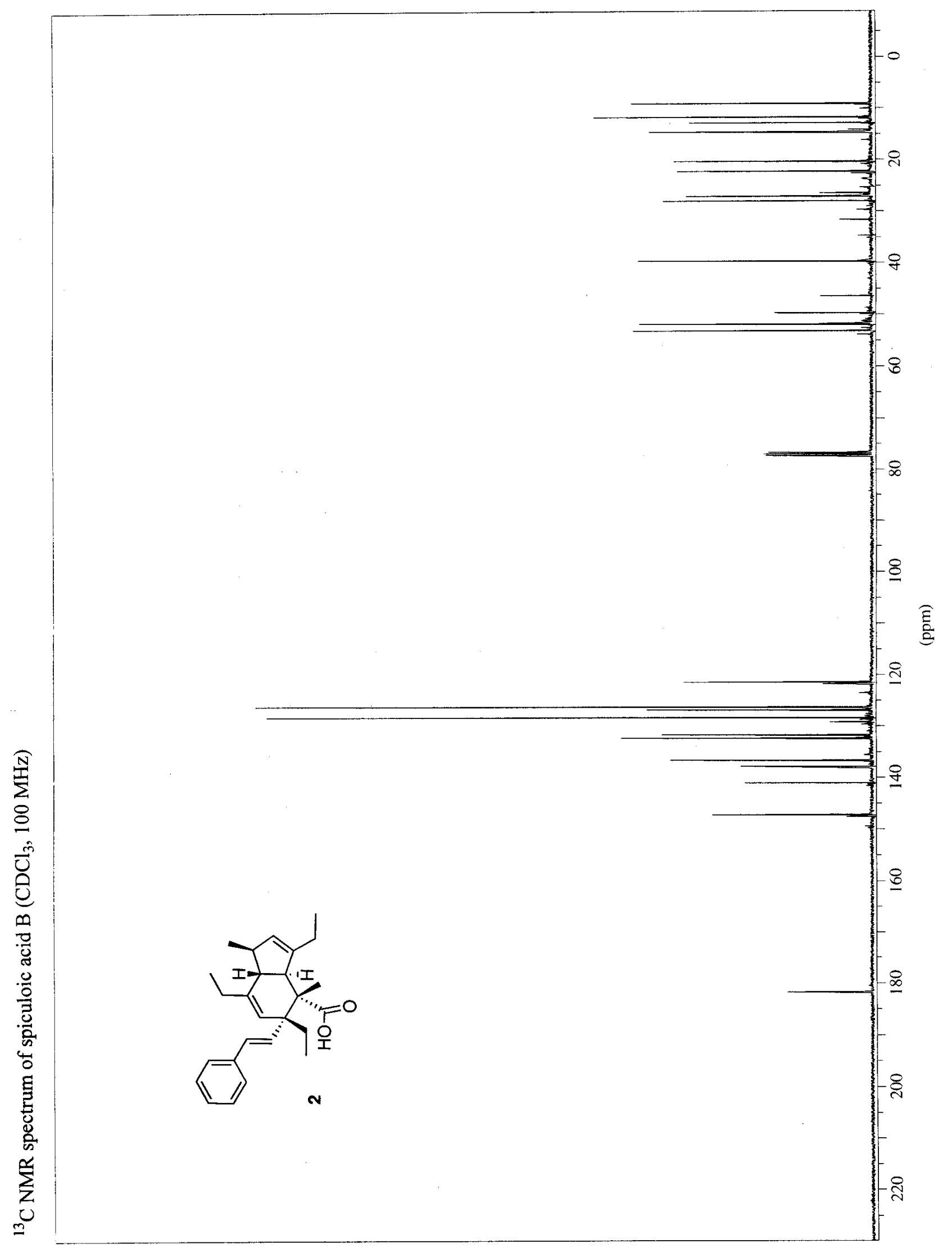

